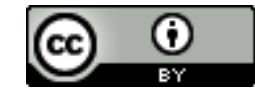

Esta obra está sob o direito de Licença Creative Commons Atribuição 4.0 Internacional.

\title{
ANÁLISE DO PROCESSO DE FORMAÇÃO/EFETIVAÇÃO DO CURRÍCULO NA ESCOLA INDÍGENA
}

\author{
Luci Souza de Meneses ${ }^{1}$ \\ Lucília Maria da Silva Soares Barbosa ${ }^{2}$ \\ Elisângela Oliveira Tavares ${ }^{3}$ \\ Andrea Marques Vanderlei Fregadolli ${ }^{4}$
}

\section{RESUMO}

O currículo é um elemento fundamental no contexto escolar, tendo em vista que ele orienta o trabalho do docente e a aprendizagem do educando. Através dos seus determinantes ele produz muitas representações nos grupos sociais, na escola e em seus agentes, professores, equipe pedagógica e alunos, e no contexto em que estão inseridos. Nesse sentido a educação escolar indígena destaca-se por fomentar a aprendizagem e o ensinamento sobre a história e cultura indígena a partir dos métodos de concepção nacional, exibindo os mitos, a religião, suas lutas e suas aquisições, bem como seu legado cultural para a história da humanidade, modificando assim os paradigmas outrora estabelecidos. Considerando que se faz necessário questionar a respeito da construção de um currículo específico para as escolas indígenas, visando estabelecer e/ou efetivar uma educação diferenciada, o presente artigo através de uma revisão de literatura de natureza qualitativa objetiva refletir sobre o processo de formação/efetivação do currículo na escola indígena. Pressupondo que as relações ocorrem nas instituições escolares baseadas na pluralidade e interculturalidade, acredita-se ser de grande importância estimular a construção de um currículo na educação escolar indígena que oriente o respeito às diferenças a uma formação significativa a partir da realidade dos educandos, favorecendo assim, uma formação diferenciada nas múltiplas dimensões do ser em sociedade.

Palavras-chave: Educação Indígena. Currículo. Currículo na Educação Escolar Indígena.

Submetido em março de 2020 e aceito em maio de 2020.

\footnotetext{
${ }^{1}$ Mestre em Educação pela Absoulute Christian University. Doutoranda do Curso de Pós-Graduação em Educação, Absoulute Christian University. em Educação pela Absoulute Christian University.

${ }^{2}$ Mestre em Educação pela Absoulute Christian University. Doutoranda do Curso de Pós-Graduação em Educação, Absoulute Christian University. em Educação pela Absoulute Christian University.

${ }^{3}$ Especialista em Docência do Ensino Superior a Distância (UFAL).

${ }^{4}$ Doutora em Ciências (UFAL). Mestre em Modelagem Computacional do Conhecimento (UFAL). Professora da graduação de Medicina e do Mestrado Ensino na Saúde da Faculdade de Medicina (UFAL).
} 


\section{INTRODUÇÃO}

O currículo é um elemento fundamental no contexto escolar, tendo em vista que ele orienta o trabalho do docente e a aprendizagem do educando. Os estudos sobre o currículo são antigos, sabe-se que as teorias sobre o currículo começaram a ter maior importância a partir da história da democratização da sociedade nos anos de 1970, cujos debates acabaram trazendo influências para as escolas, para a comunidade acadêmica, para o discurso político, bem como para a formação profissional. Dessa forma $o$ currículo passou a ser foco de interesse público e influencia as políticas educacionais (MATTOS, 2013).

Considerando que há diferentes maneiras de definir o currículo é possível compreendê-lo como "uma construção histórica e socialmente determinada e refere-se a uma prática condicionadora de si mesmo e de sua teorização" (MATTOS, 2013). Assim, através dos seus determinantes, o currículo produz muitas representações nos grupos sociais, na escola e em seus agentes, professores, equipe pedagógica e alunos, e no contexto em que estão inseridos. Ele é constituído pelas práticas educativas, pelas ações dos docentes e pelas interações estabelecidas entre o professor, o aluno e os conteúdos.
Nesse sentido a educação escolar indígena destaca-se por fomentar a aprendizagem e o ensinamento sobre a história e cultura indígena a partir dos métodos de concepção nacional, exibindo os mitos, a religião, suas lutas e suas aquisições, bem como seu legado cultural para a história da humanidade, modificando assim os paradigmas outrora estabelecidos, abdicando velhas práticas educacionais que, abordavam a história indígena como um processo de escravização.

Embora os povos indígenas tenham conquistado o direito de ter uma educação escolar diferenciada, específica, intercultural e bilíngue, percebe-se que afirmam que "os desafios persistem na efetivação de direitos históricos garantidos pelos povos indígenas que veem a educação como um processo distinto da forma como compreendem as sociedades eurodescendentes" (SCARAMUZZA; NASCIMENTO, 2018).

$\mathrm{O}$ presente artigo se insere nesse contexto, que através de uma revisão de literatura de natureza qualitativa objetiva refletir sobre o processo de formação/efetivação do currículo na escola indígena. Tal reflexão permite apontar certo impasse e/ou luta das comunidades indígenas com o Estado, no sentido de que a educação escolar indígena possui uma forma própria pedagógica que ainda é norteada pelo contexto da escola 
tradicional. Dessa forma se faz necessário questionar a respeito da construção de um currículo específico para as escolas indígenas, visando atender a educação

\section{METODOLOGIA}

O presente estudo se desenvolveu por meio de uma revisão de literatura de natureza qualitativa.

Para a produção desta pesquisa inicialmente foi estabelecida identificação do tema: "Análise do processo de formação/efetivação do currículo na escola indígena".

Em seguida, no que se refere à segregação das fontes adquiridas foram utilizadas bases de dados online por meio dos descritores: "Educação Indígena. Currículo. Currículo na Educação Escolar Indígena".

A fim de determinar as informações relevantes que seriam extraídas na revisão

\section{RESULTADOS E DISCUSSÕES}

\section{O currículo, suas concepções e sua função no contexto escolar}

$\mathrm{O}$ século $\mathrm{XX}$ trouxe mudanças nas mais diversas áreas: política, economia, segurança, educação e tecnologia. Essas mudanças ou evolução para alguns especialistas e nem tanto para seus críticos possibilitaram a criação de um novo cenário diferenciada, uma vez que a composição do currículo escolar indígena não dispõe de disciplinas específicas que abordem suas culturas.

das fontes foram utilizadas como critérios de inclusão, livros, artigos e dissertações na íntegra no idioma português, e como critério de exclusão os trabalhos que não eram gratuitos, os repetidos e os que não atendiam ao objetivo da pesquisa.

Para recolher e avaliar as fontes foi realizada uma investigação nos resumos correspondentes ao resultado da busca mediante as palavras-chave e selecionados os que citavam o currículo na educação escolar indígena. Assim, esta abordagem foi escolhida por não parcelar a realidade em unidades passíveis de mensurações para estudá-las separadamente, visto que se buscam nos fenômenos dessa situação pesquisada as inter-relações e influências mútuas.

para a educação, levando as pessoas a buscarem novas formas de compreender o mundo e suas modificações (MATTOS, 2013). O autor afirma que "a globalização e as mudanças por ela provocadas também atingiram a educação e a sua forma de atuar na sociedade - sua função, seus objetivos, sua missão, os valores e princípios pelos quais a educação se constrói”. 
Desde que a instituição escolar foi organizada seu atendimento era ofertado à elite e à funcionários importantes do Estado. Esse atendimento também se destinava à preservação de princípios dominantes, através da transmissão de informações e condutas que interessava a quem mantinha o poder (MATTOS, 2013).

Com as mudanças nas estruturas das sociedades, a industrialização e o crescimento de uma nova classe de poder e da necessidade de pessoas para o trabalho e a melhor formação para poder atender à demanda, as escolas passaram a ter função de preparar pessoas para o mundo do trabalho. Passou a existir dois tipos de instituições escolar: a das elites e a dos pobres (MATTOS, 2013).

A transformação para uma escola de massas trouxe uma série de problemas para o atendimento da demanda crescente. A escola era ineficiente, pois não contribuía para o ajustamento das novas gerações e não preparava a mão de obra para o mercado. Com as dificuldades, os governos iniciaram um processo de reavaliação da escola, de sua estrutura e das relações com a sociedade. Nesse processo de transformação, o currículo representou um dos temas mais debatidos (MATTOS, 2013).

Diante disso, Mattos (2013, p. 12) aponta alguns questionamentos: "como o currículo pode ser definido? $\mathrm{O}$ que ele inclui? O que distingue de outros conceitos e sistemas com ele relacionados?". É possível afirmar que o currículo não possui um sentido único, pois existe uma diversidade de definições e de conceitos em função das linhas de pesquisa e das percepções dos seus pensadores.

No Grande Dicionário Houaiss, uma das definições de currículo é "programação de um curso ou de uma matéria a ser examinada” (CURRÍCULO, 2020). Segundo Hamilton (1922 apud SANTOS, 2002, p. 156), a palavra "currículo" foi registrada pela primeira vez em 1633, no Oxford English Dictionary, como um curso inteiro seguido pelos estudantes. Etimologicamente, "currículo" vem do latim curriculum e significa carreira, curso, lugar onde se corre ou percurso a seguir (PORTO, 2017).

O termo até parece simples, mas carrega consigo o peso de transformar alguma coisa, pois indica movimento, algo que se move ao longo de determinado tempo.

Ribeiro (1993, p. 11 apud Mattos, 2013, p. 12) esclarece que uma das concepções mais comuns é aquela que identifica o currículo "como o elenco e sequência de matérias ou disciplinas propostas para todo o sistema escolar, um ciclo de estudos, um nível de escolaridade ou um curso, visando a graduação dos alunos nesse sistema, ciclo, nível ou curso". 
Com essa acepção entende-se que o currículo pode ser confundido com plano de estudos, onde um conjunto estruturado de matérias ou disciplinas de ensino, que se estabelece em um determinado tempo e espaço em atenção às necessidades de aprendizagens dos alunos.

Em outras palavras, no caso do currículo escolar, esse termo indica um percurso a ser seguido pelo aluno. Assim, “o currículo representa a caminhada que o sujeito irá fazer ao longo de sua vida escolar, tanto em relação aos conteúdos apropriados quanto às atividades realizadas sob a sistematização da escola" (LIMA et al., 2012).

O currículo pode ainda ser identificado por outro conceito, sendo concebido como programas de ensino em uma determinada área de estudo. $\mathrm{O}$ currículo, nesse caso, representa uma listagem, um esquema ou um sumário de temas e tópicos por área disciplinar e, muitas vezes, acompanha sugestões metodológicas de como tratar esses conteúdos programáticos. "Essas concepções destacam duas ideias independentes: uma de organização curricular e outra de disciplinas (matérias), conteúdos programáticos e respectivas observações didáticas" (MATTOS, 2013, p.12).
Percebe-se que não é uma tarefa fácil conceituar o termo "currículo", tendo em vista que ele não tem um sentido único. Há uma diversidade de sentidos e definições, dependendo da linha de pesquisa de cada autor. Porto (2017) afirma que "as diversas definições e conceituações levam ao que alguns autores chamam de polissemia, ou seja, aos vários sentidos e significados que o termo representa, sem que se chegue a um consenso entre essas interpretações".

Moreira e Candau (2008) ressaltam que "à palavra currículo associam-se distintas concepções, que derivam dos diversos modos de como a educação é concebida historicamente, bem como das influências teóricas que afetam e se fazem hegemônicas em um dado momento".

Considerando que não se pode correr o risco de aceitar apenas uma ou outra melhor concepção de currículo, se faz necessário esclarecer que é imprescindível conhecer as mais variadas acepções de maneira contextualizada, uma vez que deve-se compreender como o currículo tem sido abordado pelos diferentes autores (Quadro 1) e teorias e avaliar quais desses conceitos estão mais próximos de atender às necessidades do contexto educativo em que se encontram inseridos (PORTO, 2017). 
Quadro 1 - O Currículo segundo diferentes autores.

\begin{tabular}{|l|l|}
\hline \multicolumn{1}{|c|}{ AUTORES } & \multicolumn{1}{c|}{ CONCEPÇÕES DE CURRÍCULO } \\
\hline Foshay, 1969 & $\begin{array}{l}\text { Currículo é o conjunto de todas as experiências que o aluno adquire, sob a } \\
\text { orientação da escola. }\end{array}$ \\
\hline Saylor, 1966 & $\begin{array}{l}\text { Currículo engloba todas as experiências de aprendizagem proporcionadas pela } \\
\text { escola. }\end{array}$ \\
\hline Phenix, 1958 & $\begin{array}{l}\text { Currículo é o modelo organizado do programa educacional da escola e descreve } \\
\text { a matéria, o método e a ordem de ensino - o que, como e quando se ensina. }\end{array}$ \\
\hline Johnson, 1977 & $\begin{array}{l}\text { Currículo é uma série estruturada de resultados de aprendizagem que se tem em } \\
\text { vista. O currículo prescreve (ou, pelo menos, antecipa) os resultados do ensino; } \\
\text { não prescreve os meios. }\end{array}$ \\
\hline
\end{tabular}

Fonte: Mattos, 2013.

Dentre as definições acima apresentadas Ribeiro (1993 citado por MATTOS, 2013) esclarece que as duas primeiras "possuem um traço em comum: conjunto de experiencias educativas vividas pelos alunos, sob a tutela da escola". Entretanto, a segunda definição vista no quadro 01 se refere às experiencias educativas e de aprendizagem organizadas pela escola. A primeira e a segunda definições mostradas, segundo o autor, apresentam uma estreita associação entre "experiências de aprendizagem ou educativa" e "currículo". O currículo nesse caso, seria uma "acumulação de experiências educativas ou o itinerário formativo do aluno durante sua passagem pela escola [e, ao mesmo tempo], seria o conjunto variado"

$$
\text { Para Moreira (1997 apud }
$$
MATTOS, 2013, p. 24) dois aspectos merecem destaques e devem ser considerados nas definições: "conhecimento escolar e experiencia de aprendizagem".

No primeiro, o currículo refere-se ao conhecimento transmitido pela escola de maneira pedagógica e didática, como um conjunto de disciplinas, sendo aplicado pelo aluno. No segundo aspecto, o currículo está focado nas diferenças individuais e na preocupação com as atividades do aluno, e o termo refere-se aos caminhos que esse aluno percorre em sua formação. "Dessa forma, o currículo passa a significar o conjunto de experiências a serem vividas pelo estudante sob orientação da escola" (MATTOS, 2013, p. 24).

Devido à sua ampla complexidade o currículo pode ainda ser compreendido a partir de diferentes pontos de vista teóricos. Segundo Porto (2017, p. 42) "uma teoria curricular pode ser entendida como um conjunto de conhecimentos, estratégias e aplicações de ensino que estão, de algum modo, organizados e sistematizados na 
esfera da proposta de um projeto pedagógico".

Tendo em vista que o sistema educacional é um conjunto de ações, métodos e estruturas através dos quais se dá o processo de formação e/ou educação, pode-se afirmar que o currículo é um componente desse sistema. Com isso, compreende-se que o currículo escolar são "os conhecimentos ou saberes produzidos pelo homem ao longo de sua história e selecionados pela escola para se constituírem em saberes ou conhecimento escolar" (SANTOS, 2002, p. 159).

Dessa forma o currículo funcionaria como um quadro de referência, a substância do sistema educativo. Mattos (2017) afirma que com base em sua elaboração é possível distinguir alguns tipos de currículos, e exemplifica (Quadro 2):

Quadro 2 - Tipos de Currículos, segundo Mattos (2017).

\begin{tabular}{|l|l|}
\hline \multicolumn{1}{|c|}{ TIPO } & \multicolumn{1}{c|}{ CARACTERÍSTICAS } \\
\hline Formal & $\begin{array}{l}\text { São propostas de ensino que envolvem projeto pedagógico e planos de trabalho } \\
\text { em sala de aula. }\end{array}$ \\
\hline Real & $\begin{array}{l}\text { São propostas desenvolvidas em sala de aula que incluem às experiências dos } \\
\text { alunos na escola. }\end{array}$ \\
\hline Vazio ou nulo & $\begin{array}{l}\text { O que não é trabalhado pelo currículo da escola e que representa omissões ou } \\
\text { ausências. }\end{array}$ \\
\hline Oculto & $\begin{array}{l}\text { Em linhas gerais, são as experiências vivenciadas na escola, mas que não estão } \\
\text { organizadas em uma proposta pedagógica ou em uma grade curricular. Aqui } \\
\text { estão incluídos conteúdos trabalhados ou abordados de maneira não intencional } \\
\text { pelos professores ou alunos. Ele pode transmitir valores positivos ou negativos. }\end{array}$ \\
\hline
\end{tabular}

Fonte: Mattos (2017, p. 14).

É possível perceber que o currículo oferece um leque de possibilidades de questões inerentes à sua finalidade $\mathrm{e}$ composição conteúdos escolares no decurso do ano letivo, bem como o desenvolvimento desses conteúdos que serão elementos condicionantes para o trabalho do educador e do educando (ARROYO, 2007).

Arroyo (2007, apud Laccino, 2013, p. 18) “destaca que os currículos condicionam o trabalho docente, ou seja, o currículo, os conteúdos, a ordem e a sequência em que são trabalhados tais conteúdos, as hierarquias que assumem e as cargas horárias, são o fundamento estrutural do cotidiano escolar".

Para Arroyo (2007), refletir acerca do currículo, considerando a possibilidade de reorienta-lo podem ser a forma de fazer com que os professores possam desenvolver e/ou expor uma nova identificação de docente, onde adotará uma consciência renovada tornando-se assim, um novo profissional, tendo em vista que o currículo objetiva proporcionar a inclusão social, desenvolvendo através disso a consciência 
do grupo, de forma que estes possam comprometer-se com os princípios e paradigmas de conduta existentes, não atuando somente seguindo uma regra e uma série de conteúdo a ser trabalhados.

Neste sentido, Arroyo (2007) ainda destaca que "as indagações sobre o currículo vindas da nova consciência e identidade profissional nos levam a repensar as lógicas e valores que estruturam a organização curricular [...] repensar e superar lógicas estruturantes dos currículos que afetam a estrutura de trabalho, de tempos e até as hierarquias profissionais [...]". O autor ressalta que os professores que adquirem uma nova "consciência profissional vêm criando formas de preparar seu trabalho e reagir contra a condição de aulistas" através de uma atuação desenvolvida coletivamente (ARROYO, 2007)

Deste modo, uma forma de conduzir o currículo para o dia-a-dia profissional vem da atuação participativa em conjunto com toda equipe pedagógica, onde poderão esquematizar, estabelecer, reestruturar e definir prioridades e tarefas, permitindo, com isso, que o currículo seja construído por todos (ARROYO, 2007).

Deve-se destacar que a elaboração do currículo não é um processo modesto, imparcial e abnegativo, mas, sim, um processo social de seleção e organização de saberes e valores que serão ensinados nas escolas. "Esse processo é perpassado por disputas e lutas, diante dos interessados divergentes e conflitos simbólicos e culturas presentes na sociedade e relacionados a visões e concepções distintas sobre a educação e seus objetivos" (SANTOS, 2002, p. 161).

Diante disso, compreende-se que o currículo apresenta todo um mecanismo de sugestões que precisam ser escolhidas e desenvolvidas conforme com a comunidade em que a instituição escolar encontra-se inserida, proporcionando um trabalho em que as mais variadas ações para a melhoria do ensino sejam envolvidas, objetivando com isso que os educandos aprendam efetivamente.

\section{O currículo no contexto da educação escolar indígena}

\section{A Educação Indígena é} caracterizada pela metodologia habitual de aquisição de conhecimentos e costumes intrínsecos de cada etnia. Sobrinho, Souza e Bettiol (2017) afirmam que "estes saberes/conhecimentos são ensinados/aprendidos de forma oral no dia a dia, nos rituais, nos mitos e nas distintas formas de organização de cada comunidade". Como se sabe o contato entre os colonizadores e os povos colonizados iniciou um processo de aculturação que marcou a história da sociedade brasileira, onde os povos indígenas e africanos foram 
brutalmente escravizados visando o progresso e a riqueza dos colonizadores.

Para Lima et al (2017) “A história brasileira mostra que a relação entre o Estado e os povos indígenas foi pautada pela dominação, por meio da integração e homogeneização cultural, ao invés do pluralismo cultural". Assim, esses procedimentos, que envolviam a escravização dos povos indígenas, bem como as iniciativas de catequizá-los e domesticá-los, aumentou consideravelmente as desigualdades sociais vivenciadas por esse grupo étnico até os momentos atuais.

No que se refere à história da educação escolar indígena, o que se sabe é que desde o início da colonização até a promulgação da Constituição Federal (CF) de 1988, os programas educacionais fundamentaram-se na desvalorização e abandono das referências culturais e práticas sociais indígenas, objetivando assim incorporar os valores e significados europeus (AFONSO, 2016).

Nesse sentido Silva e Freitas (2014) afirmam que "todas as iniciativas educativas implementadas por meio das políticas indigenistas anteriores à
Constituição Federal de 1988, tinham como o propósito de realizar um trabalho pedagógico na perspectiva de abolir com as especificidades étnicas e culturais e por meio da negação a sociodiversidade do Brasil”.

Embora os colonizadores tenham tentado integrar os povos indígenas à sociedade brasileira através de uma educação assimilacionista, excluindo as culturas e valores indígenas, o que se percebeu é que tal modelo educacional "não conseguiu efetivamente desconstruir suas identidades e seus sentimentos de pertencimento a um povo que não queria perder suas origens e referências indenitárias". Desse modo, os povos indígenas brasileiros lutaram para manter viva as culturas, "mostrando que em suas comunidades é presente a coexistência de costumes ancestrais com traços culturais recentes" (PESSOA, 2017, p. 210).

No Quadro 3, Silva e Freitas (2014) apresentam as políticas de atendimento educacional destinados aos povos indígenas, compreendido entre o período colonial e a publicação da Constituição de 1988. 
Quadro 3 - Políticas de atendimento educacional destinadas aos povos indígenas, da colônia a CF/1988.

\begin{tabular}{|c|c|c|c|}
\hline $\mathbf{N}^{\mathbf{o}}$ & PERÍODO & LEGISLACÕ̃ES & CARACTERÍSTICAS \\
\hline 01 & 1686-1759 & $\begin{array}{l}\text { Lei de } 21 / 12 / 1686 \quad- \\
\text { Regimento das Missões }\end{array}$ & - Catequese. \\
\hline 02 & $1757-1798$ & Diretório dos Índios & $\begin{array}{l}\text { - Imposição cultural e negação da diferença; } \\
\text { - Educação Escolar impositiva e } \\
\text { assimilacionista. }\end{array}$ \\
\hline 03 & $1798-1845$ & Carta Régia & • Não faz referência a educação escolar. \\
\hline 04 & $1845-1889$ & $\begin{array}{l}\text { Decreto } \quad \mathrm{n} .426 / 1845 \\
\text { Regulamento das Missões }\end{array}$ & $\begin{array}{l}\text { - Imposição cultural e negação da diferença; } \\
\text { - Catequese e Educação. }\end{array}$ \\
\hline 05 & 1910-1967 & $\begin{array}{l}\text { Decreto n. } \quad 8.072 / 1910 \\
\text { Criação do SPI }\end{array}$ & $\begin{array}{l}\text { - Alegou-se uma preocupação com diversidade } \\
\text { linguística e cultural dos povos indígenas; }\end{array}$ \\
\hline 06 & 1967-1991 & $\begin{array}{l}\text { Lei 5.371/1967 Criação da } \\
\text { FUNAI }\end{array}$ & - Ensino laico de caráter integracionista. \\
\hline 07 & 1988 & Constituição Federal de 1988 & $\begin{array}{l}\text { - Reconhecimento e valorização da diferença } \\
\text { indígena. }\end{array}$ \\
\hline
\end{tabular}

Fonte: Silva e Freitas (2014, p. 10).

A partir da promulgação da Constituição de 1988 quando "novas políticas culturais são definidas e novos grupos sociais ganham visibilidade no campo histórico-cultural e patrimonial" (VOLKMER et al., 2015, p. 53), vários povos indígenas perceberam que a educação escolar seria um meio de reduzir a desigualdade existente, e com isso estabeleceriam seus direitos e suas conquistas, além de promover um “diálogo intercultural entre diferentes agentes sociais" (SOBRINHO; SOUZA; BETTIOL, 2017, p. 59).

Desse modo, Nessa luta pelo reconhecimento da sociedade, os indígenas brasileiros no século XX, tendo a orientação e o apoio de vários representantes dos movimentos sociais, além de lutar pelo direito às suas terras, empreenderam também uma luta pelo direito à uma Educação Escolar Indígena, onde suas culturas e seus saberes fossem fortalecidos e valorizados (PESSOA, 2017). Com isso, observa-se que nas últimas décadas, através desses movimentos de afirmação étnica, um novo modelo escolar surgiu no cenário educacional brasileiro: a escola dos e para os povos indígenas, protegida por leis que determinaram um paradigma individualizado e específico de educação escolar.

A fim de que seja possível entender o desenvolvimento da educação escolar indígena brasileira, se faz necessário conhecer a legislação que assegura as políticas públicas implementadas nessa área. 
Quadro 4 - Bases Legais Sobre a Educação Escolar Indígena.

\begin{tabular}{|c|c|}
\hline LEGISLAÇÃ̃ & CARACTERÍSTICA \\
\hline Constituição Federal de 1988. & Artigos 210 e 231. \\
\hline Decreto n. 26/1991 & Dispõe sobre Educação Escolar para as populações indígenas. \\
\hline $\begin{array}{l}\text { Diretrizes para a Política } \\
\text { Nacional de } \text { Educação } \\
\text { Escolar Indígena } 1993\end{array}$ & $\begin{array}{l}\text { Este documento pretende informar sobre as atividades e programas } \\
\text { desenvolvidos no âmbito do Ministério da Educação e do Desporto } \\
\text { em relação ao atendimento. Educacional às comunidades indígenas }\end{array}$ \\
\hline $\begin{array}{l}\text { Lei 9394/1996. Diretrizes e } \\
\text { Bases da Educação }\end{array}$ & Artigo 78 e 79 \\
\hline $\begin{array}{l}\text { Referencial Curricular } \\
\text { Nacional para as escolas } \\
\text { Indígenas (rcnei)/1988 }\end{array}$ & $\begin{array}{l}\text { Disponibilizar informações a fim de que fosse elaborado programas } \\
\text { de educação escolar que atendessem aos anseios e aos interesses dos } \\
\text { povos indígenas, considerando os fundamentos da pluralidade } \\
\text { cultural e da igualdade entre todos os brasileiros (BRASIL, 1998). }\end{array}$ \\
\hline $\begin{array}{l}\text { Parecer } n^{\circ} 14 / 99 \text { do Conselho } \\
\text { Nacional de Educação. }\end{array}$ & $\begin{array}{l}\text { A Câmara de Educação Básica organizou diretrizes curriculares para } \\
\text { os diferentes níveis e modalidades de ensino, determinando a } \\
\text { estrutura e funcionamento da escola } \\
\text { Indígena e propõe ações concretas em prol da Educação Escolar } \\
\text { Indígena. }\end{array}$ \\
\hline $\begin{array}{lll}\text { Resolução } & \mathrm{n}^{\mathrm{o}} \quad 3 / 99 & \text { do } \\
\text { Conselho } & \text { Nacional } & \text { de } \\
\text { Educação. } & & \\
\end{array}$ & $\begin{array}{l}\text { Fixa as diretrizes nacionais para o funcionamento das escolas } \\
\text { indígenas }\end{array}$ \\
\hline $\begin{array}{l}\text { Plano Nacional de Educação } \\
\text { (PNE), Lei n. } \\
\text { 10.172/2001. }\end{array}$ & $\begin{array}{l}\text { Apresenta um capítulo sobre a Educação Escolar Indígena, dividido } \\
\text { em três partes. Na primeira parte, encontra-se uma breve análise de } \\
\text { como tem sido ofertado a educação escolar aos povos indígenas. Na } \\
\text { segunda parte, são apresentadas as diretrizes para a Educação Escolar } \\
\text { Indígena. E na terceira parte, são expostos os objetivos e metas que } \\
\text { deverão ser atingidos a curto e a longo prazos. }\end{array}$ \\
\hline $\begin{array}{ll}\text { Referenciais para a Formação } \\
\text { de } & \text { Professores } \\
\text { Indígenas/2002. } & \end{array}$ & $\begin{array}{l}\text { Visava construir referenciais e orientações que possam nortear a } \\
\text { tarefa de implantação permanente de programas de formação de } \\
\text { professores indígenas, de modo que atendam às demandas das } \\
\text { comunidades indígenas e às exigências legais de titulação do } \\
\text { professorado em atuação nas escolas indígenas do país (BRASIL, } \\
\text { 2002, p.9). }\end{array}$ \\
\hline Lei $11.645 / 2008$. & $\begin{array}{l}\text { Inclui no currículo oficial da rede de ensino a obrigatoriedade da } \\
\text { temática "História e Cultura Afro-Brasileira e Indígena". }\end{array}$ \\
\hline Decreto 6861/2009. & $\begin{array}{l}\text { Dispõe sobre a Educação Escolar Indígena, define sua organização } \\
\text { em territórios etnoeducacionais, e dá outras providências. }\end{array}$ \\
\hline Lei no $12.711 / 2012$. & $\begin{array}{l}\text { Dispõe sobre ações afirmativas para afrodescendentes e indígenas. } \\
\text { Art. } 60 \text {. }\end{array}$ \\
\hline $\begin{array}{l}\text { Decreto } 7747 \text { de } 05 \text { de junho } \\
\text { de } 2012 .\end{array}$ & $\begin{array}{l}\text { Institui a Política Nacional de Gestão Ambiental e Territorial das } \\
\text { Terras Indígenas. Art. 4, VII, Eixo } 7 .\end{array}$ \\
\hline $\begin{array}{l}\text { Resolução } \text { CEB/CNE } \mathrm{n}^{\circ} \\
05 / 2012 .\end{array}$ & $\begin{array}{l}\text { Define Diretrizes Curriculares Nacionais para a Educação Escolar } \\
\text { Indígena na Educação Básica. Art. 14, parágrafos } 3^{\circ} \text {. e } 6^{\circ} \text {. }\end{array}$ \\
\hline $\begin{array}{l}\text { Portaria do Ministério da } \\
\text { Educação MEC N } 389 \text {, de } 09 \\
\text { de maio de } 2013 .\end{array}$ & $\begin{array}{l}\text { Cria o Programa Nacional de Bolsa Permanência para estudantes de } \\
\text { graduação ingressantes em universidades e institutos federais. }\end{array}$ \\
\hline $\begin{array}{l}\text { Portaria do Ministério da } \\
\text { Educação GM/MEC no } \\
1.062 \text {, de } 30 \text { de outubro de } \\
2013 \text {, institui o Programa } \\
\text { Nacional dos Territórios } \\
\text { Etnoeducacionais - PNTEE }\end{array}$ & $\begin{array}{l}\text { Consiste em um conjunto articulado de ações de apoios técnico e } \\
\text { financeiro do MEC aos sistemas de ensino, para a organização e o } \\
\text { fortalecimento da Educação Escolar Indígena, conforme disposto no } \\
\text { Decreto no } 6.861 \text {, de } 27 \text { de maio de } 2009 \text {. }\end{array}$ \\
\hline
\end{tabular}


Diante do exposto no quadro acima percebe-se que as ações destinadas à educação escolar indígena fez dela atualmente o agrupamento dos direitos políticos e culturais dos povos indígenas brasileiros, sendo portanto, uma modalidade de ensino inclusivo que foi reivindicada por lideranças, comunidades e professores indígenas que fizeram parte das lutas dos povos indígenas pela garantia e proteção territorial e pelo reconhecimento da diversidade sociocultural, específicas da constituição da cidadania indígena no Brasil.

Os povos indígenas diferenciam o termo educação indígena, da educação escolar, Sobrinho, Souza e Bettiol (2017, p. 59) explicam que "a educação indígena é responsável pela aquisição das tradições, costumes e saberes específicos da comunidade, da etnia a qual o indivíduo pertence; já a educação escolar complementa os conhecimentos tradicionais e garante o acesso aos códigos escolares não indígenas”.

Assim, quando os povos indígenas foram reconhecidos como uma organização social, capaz de produzir sua cultura e transmiti-la por meios de processos específicos de aprendizagem, tendo seus próprios estabelecimentos educativos nas aldeias, lhes foi assegurado direitos de ter autonomia e determinação. Desse modo, em termo conceitual, pode-se afirmar que a educação escolar indígena é uma categoria que tanto sob o aspecto jurídicoadministrativo quanto sob o aspecto político-pedagógico, na medida em que a Carta Magna assegura o direito das sociedades indígenas a uma educação escolar diferenciada, específica, intercultural e bilíngue.

Essa conquista permitiu que a Educação Escolar Indígena assumisse uma nova referência, onde a pedagogia assimilacionista foi abandonada, implantando assim, uma educação fundamentada no respeito à autonomia e ao contexto cultural de cada comunidade indígena. Tal fato também provocou mudanças em alguns costumes, hábitos dos povos indígenas, bem como na forma como as comunidades se organizavam, afetando também a estrutura escolar das aldeias.

Nesse procedimento ativo, cabe ao Estado nortear as mudanças curriculares, visando atingir os propósitos para os quais a educação escolar indígena se propõe, estabelecendo um diálogo entre os sujeitos, de como que seja encontrado um ponto de concordância entre as distintas preferências e ideologias existentes que transpõem essas negociações. Deste modo, entende-se que não existe um currículo padrão, mas iniciativas para aproximar-se do que se almeja, a partir das solicitações dos povos indígenas, dos referenciais determinados na legislação e das discussões teóricas atuais. 
A LDB 9.394/96 destaca em seu art. 26, a importância em considerar as especificidades regionais e locais da sociedade, da cultura, da economia e da clientela de cada instituição escolar, a fim de os objetivos do Ensino Fundamental sejam obtidos. No que se refere às escolas indígenas, Grupioni (2005) aponta que "para que seja garantida uma educação diferenciada, não é suficiente que os conteúdos sejam ensinados por meio do uso das línguas maternas: é necessário incluir conteúdos curriculares propriamente indígenas e acolher modos próprios de transmissão do saber indígena".

Dessa forma, construir um currículo para as escolas indígenas implica oportunizar que esses povos se tornem atores principais da própria educação onde poderão garantir seus direitos fazendo com que sua cultura seja respeitada.

\section{Considerando que "a} interculturalidade tenta promover relações dialógicas e igualitárias entre pessoas e grupos que pertencem a universos culturais diferentes, trabalhando os conflitos inerentes a esta realidade" (CANDAU, 2006; YONG, 2016), pode-se afirmar que a educação intercultural é uma prática social que possibilita relacionar-se profundamente com as diferentes dinâmicas da escola. Relacionando essa acepção de educação intercultural com a realidade da educação indígena compreende-se que "no campo da educação escolar indígena, diferentes interpretações acerca da interculturalidade e/ou diálogo intercultural enquanto proposta e projeto educativo têm causado muitas controvérsias" (NASCIMENTO, QUADROS; FIALHO, 2016, p. 196). Uma vez que quando se reflete sobre a práxis da interculturalidade no dia a dia das escolas indígenas pode-se supor que o modelo de educação assimilacionista será rompido, embora tal prática pedagógica ainda predomine em muitas aldeias.

O currículo das escolas indígenas pode ser compreendido como "um conjunto de demandas que aludem ao problema do reconhecimento na esfera pública em face das situações de preconceito e reclamam o direito à diferença, negado no modelo já referido da educação escolar para os índios" (NASCIMENTO, 2017). Com isso, é preciso considerar a construção de um currículo específico que atenda às necessidades das comunidades indígenas garantindo assim, uma educação diferenciada. Nesse sentido, deve-se ressaltar que "a percepção dos indígenas sobre o papel da escola diferenciada está ligada às disputas simbólicas e também materiais, uma vez que são reivindicados recursos específicos que constituem as políticas de educação escolar indígena" (NASCIMENTO, 2017).

Entende-se que a assimilação dos conhecimentos exteriores é indispensável, 
contudo, é basilar proteger o conceito da inclusão de saberes indígenas no currículo escolar, considerando que esses podem associar-se segundo a sistematização da escola convencional sendo, entretanto, apropriados para a educação escolar indígena.

Dessa maneira ao considerar um currículo específico na Educação Escolar Indígena é necessário refletir sobre a sua flexibilidade, no sentido de que esse currículo esteja sempre acessível, e apropriado à realidade de cada comunidade. A LDB 9.394/96 em seu artigo 78 garante a construção dessa especificidade curricular para as escolas indígenas, onde estabelece é necessário “desenvolver currículos e programas específicos, neles incluindo os conteúdos culturais correspondentes às respectivas comunidades" (BRASIL, 2018, p. 34), porém, nota- se que ainda há um caminho a ser percorrido para que essa política pública seja efetivada.

De acordo com Pessoa (2017, p. 218) torna-se imprescindível "transformar o que está definido nos documentos legais em práticas educativas que realmente valorizem os saberes, a oralidade e a história de cada povo, em diálogo com os demais saberes produzidos por outras sociedades humanas". À vista disso, acredita-se que ao organizar um currículo específico e apropriado para a educação indígena sob a perspectiva intercultural, as especificidades que fazem da escola indígena diferente das demais podem ser legalizadas e postas em prática, se fazendo perceber que os saberes produzidos pelas comunidades indígenas são valorizados.

Para isso, se deve dedicar-se na preparação de um material didático específico e adequado à educação indígena, que contenha em seu conteúdo uma metodologia de educação diferenciada e intercultural, conforme estabelecido pela LDB 9.394/96 em seu artigo 78, que preconiza que se deve "elaborar e publicar sistematicamente material didático específico e diferenciado" (BRASIL, 2018, p. 34).

Nesse contexto, deve-se ressaltar a importância da formação de professores indígenas, tendo em vista que "é durante os cursos de formação de professores indígenas que o grupo discute, reflete e (re) constrói uma nova forma de se pensar e repensar suas relações, culminando com a construção de material didático para as escolas indígenas" (PESSOA, 2017, p. 218). Ademais, é sabido que os "professores preparados podem mais facilmente promover o equilíbrio entre as aquisições de conhecimento que possibilitam melhora na participação da sociedade nacional e a manutenção e afirmação de sua própria cultura, dessa forma, garantindo que cada etnia decida como se dará sua inserção na sociedade, assim, respeitando o objetivo de 
cada comunidade indígena" (SILVA; GOMES, 2018).

Assim, compreende-se que recebendo uma formação apropriada baseada na perspectiva intercultural, o professor indígena pode modificar a realidade de muitos alunos, suprimindo as

\section{CONCLUSÃO}

As sociedades são organizações edificadas histórica e socialmente, assim sendo, motivam as relações que se constituem entre as pessoas em um determinado contexto e espaço, sendo também estabelecidas por essas relações, assim como representam uma construção sociocultural.

Sob essa perspectiva, o currículo é um artefato estruturante das condições em que o indivíduo terá contato com as diferentes formas de cultura e de relacionamento. O currículo, assim, se estabelece como um método de direcionar as experiências e as conhecimentos que se pode edificar no contato com o outro. $\mathrm{O}$ currículo também se relaciona com os

\section{REFERÊNCIAS}

AFONSO, Germano Bruno. Ensino de História e Cultura Indígenas. Curitiba: Intersaberes, 2016.

ARROYO, Miguel Gonzáles. Pedagogias em movimento - o que temos a aprender dos Movimentos Sociais? Currículo Sem práticas assimilacionistas, bem como as entendimentos preconceituosos, tornando a escola indígena em uma educação efetivamente intercultural predisposta ao diálogo reflexivo, onde a construção do currículo valoriza e respeita as diferenças existentes.

saberes que a sociedade indígena e não indígena desenvolveu e construiu no decorrer do tempo. Sua efetivação na escola demanda preparação de planos de ensino e a organização de conteúdo.

É sabido que a escola atua como um elemento participante da sociedade, idealizada entre a diversidade coletiva e individual. Pressupondo que as relações ocorrem nas instituições escolares baseadas na pluralidade e interculturalidade, acredita-se ser de grande importância estimular a construção de um currículo na educação escolar indígena que oriente o respeito às diferenças, bem como à valorização da cultura, tendo assim um caráter intercultural, propondo com isso uma transformação social.

Fronteiras, v. 3, n. 1, p. 28-49, jan./jun. 2003.

BENTO, A. Como fazer uma revisão da literatura: Considerações teóricas e práticas. Revista JA (Associação Académica da Universidade da Madeira), no 65, ano VII (pp. 42-44). ISSN: $1647-$ 8975. 2012. 
BRASIL. $L D B$ : Lei de diretrizes e bases da educação nacional. - 2. ed. - Brasília:

Senado Federal, Coordenação de Edições Técnicas, 2018.

CAVALCANTE, M. S. N.; YONG, L. D. P. Multiculturalismo e interculturalidade: uma realidade e uma perspectiva educacional? Anuário do Instituto de Natureza e Cultura-ANINC, v. 02, n. 01, 2016.

\section{CURRÍCULO. Grande Dicionário}

Houaiss. Disponível em:

$<$ Houaiss.uol.com.br/pub/apps/www/v30/html/index.htm\#1> Acesso em: 02 dejaneiro de 2020.

FUNAI, Fundação Nacional do Índio.

Legislação. Disponível em: $<$ http://www.funai.gov.br/index.php/legcidadania>. Acesso em: 02 de janeiro de 2020.

GRUPIONI, L. D. B. As leis e a educação escolar indígena: programa parâmetros em ação de educação escolar indígena. Ministério da Educação, Secretaria de Educação Continuada, Alfabetização e Diversidade, 2a edição, 2005.

GUIMARÃES, S. G.T. D. Ressignificando os labirintos da pesquisa qualitativa: exercícios práticos de análise de discurso. Porto Alegre: EDIPUCRS, 2015.

LACCINO, M. C. R. A concepção de currículo dos profissionais da educação do centro de ensino fundamental 301 do recanto das emas: um olhar sobre a prática. Centro de Estudos Avançados Multidisciplinares. Universidade de Brasília, DF, 2013.

LIMA, M. et al. A função do currículo no contexto escolar. Curitiba: Intersaberes, 2012.

LIMA, N. F. et al. Educação e interculturalidade: a formação dos professores indígenas. Revista

Humanidades e Inovação. v. 4, n. 4, 2017.

MATTOS, A. P. Escola e currículo.

Curitiba: Intersaberes, 2014. (Série gestão educacional).

MOREIRA, A. F. B.; CANDAU, V. M. Multiculturalismo: diferenças culturais e práticas pedagógicas. São Paulo: Vozes, 2008.

NASCIMENTO, R. G. Escola como local das culturas: o que dizem os índios sobre escola e currículo. Revista Educ. Public. Cuiabá, v. 26, n. 62/1, p. 373-389, maio/ago. 2017.

NASCIMENTO, R. N. F.; QUADROS, M. T.; FIALHO, V. Interculturalidade enquanto prática na educação escolar indígena. Revista Antropológicas, 27 (1): 187-217,2016.

PESSOA, H. C. C. Narrativas de professores indígenas sobre o cotidiano escolar. Revista Ensino Interdisciplinar. v. 3, n. 08, VERN, Mossoró, RN, maio/2017.

PORTO, M. Currículos, programas e projetos pedagógicos. São Paulo: Pearson Education Brasil, 2017.

SCHMIDT, E. S. Currículo: uma abordagem conceitual e histórica. Publ. UEPG Ci. Hum., Ci. Soc. Apl., Ling., Letras e Artes, Ponta Grossa, n. 11, p. 5969, jun. 2003.

SANTOS, L. L. C. P. Problemas e divergências no campo do currículo. In: Coleção Veredas - Formação superior de professores. Mod. 3., v. 2. Belo Horizonte: SEE-MG, 2002.

SCARAMUZZA, G. F.; NASCIMENTO, A. C. Produzir a educação intercultural na escola indígena: desafios aos educadores de um novo tempo. Currículo sem 
Fronteiras. v. 18, n. 2. P. 550-565, maio/ago., 2018.

SILVA, A. R.; FREITAS, M. C. S. A institucionalização da educação escolar indígena no Brasil. Revista Científica Vozes do Vales - UFV. JM, MG - Brasil, n. 06, ano III-10/2014.

SILVA, G. A.; GOMES, V. A interculturalidade na educação indígena. Revista Saberes docentes. Juína - MT, Brasil, v. 3, n. 5, jan;/jul. 2015.

SOBRINHO, R. S. M.; SOUZA, A. S. D.; BETTIOL, C. A. A educação escolar indígena no Brasil: uma análise crítica a partir da conjuntura dos 20 anos de LDB. Unisul, Tubarão, v.11, n. 19, p. 58 - 75, Jan/Jun 2017.

VOLKMER, M. S. et al. Educação e diversidade cultural: culturas indígenas e africanas na sala de aula. Revista de História e Geografia. Santa Cruz do Sul, v. 17, n. 02, p. 52-63, jul./dez. 2015. 